Original Article

\title{
Management and Outcome of Ruptured Anterior Circulation Cerebral Aneurysms - An Experience of Neurosurgery Department of Nawabshah
}

\author{
Fahmida Arab Mallah', Abdul Razaque Mari ${ }^{1}$, Muzammil Dilbar ${ }^{1}$, Shams Raza Brohi \\ Hamid Akbar Sheikh ${ }^{1}$, Syed Aamir Shah ${ }^{3}$, Imran Mirbaher ${ }^{1}$ \\ ${ }^{1}$ Peoples University of Medical and Health Sciences for Women (PUMHSW), Nawabshah - Shaheed \\ Benazir Abad. \\ ${ }^{2}$ Suleman Roshan Medical College, Tando Adam. \\ ${ }^{3}$ Shaheed Zulfiqar Ali Bhutto Medical University (SZABMU), PIMS, Islamabad - Pakistan
}

\section{ABSTRACT}

Objectives: To analyze the management and outcome of ruptured anterior cerebral circulation aneurysm by a variety of procedures including microsurgical clipping.

Material and Methods: A quasi-experimental study, carried out in The Department of Neurosurgery, Peoples' Medical University Hospital Nawabshah from November 2010 to December 2020.We enrolled 38 patients and 40 aneurysms who presented with ruptured aneurysms. Hunt and Hess grading was used to evaluate the neurological status and ruptured aneurysms were managed by microsurgical clipping, excision, and suture ligation. The outcome was assessed by Good, Fair, Poor, and Worst at the end of one year of follow-up.

Results: Out of 38 patients Male were (23) $61 \%$ and females were (15) $39 \%$, with a mean age of $50 \pm 25$ years with aneurysmal subarachnoid hemorrhage and graded according to Hunt and Hess grade and fissure grading. Middle cerebral artery aneurysm was $45 \%$, Anterior communicating artery $30 \%$, Anterior Cerebral Artery $10 \%$, carotid bifurcation $2.5 \%$. Multiple aneurysms at internal carotid plus anterior communicating artery $(n=2)$ and internal carotid plus middle cerebral artery aneurysms $n=2$. Distal anterior cerebral $(n=1)$. In 33 patients, the aneurysm was clipped, in 3 patients with fissure grading 4 and huge intracerebral bleed with signs of brain herniation, decompression plus aneurysm clipping was done, suture ligation $(n=1)$ and excision of a giant aneurysm $(n=3)$.

Conclusions: Microsurgical clipping is considered an ideal modality to secure a ruptured intracerebral aneurysm. Rarely it can be amendable by suture ligation, or excision. Presenting Hunt and Hess, fissure grading, age, and volume of intracerebral bleed have a direct impact on prognosis.

Keywords: Aneurysms, subarachnoid hemorrhage, clipping, ligation, excision.

Abbreviation: ACA: Anterior Cerebral Artery. MCA: Middle cerebral Artery. aSAH: Aneurysmal Subarachnoid Hemorrhage. CTA: Computed Tomographic Angiography. MRA: Magnetic Resonance Angiography. DSA: Digital Subtraction Angiography. SPSS: Statistical Package for Social Services. Acom: Anterior Communicating Artery. ICA: Internal Carotid Artery. DACA: Distal Anterior Cerebral Artery Aneurysm. ICB: Intracerebral bleed. CSF: Cerebro Spinal Fluid. 
Corresponding Author: Fahmida Arab Mallah

Assistant Professor, Neurosurgery

Peoples University of Medical and Health Sciences

For Women, Nawabshah - Shaheed Benazir Abad - Pakistan

Date of Submission: 02-08-2021

Date of Revision: 28-09-2021

Date of Acceptance: 30-09-2021

Date of Online Publishing: 30-09-2021

Date of Print: 30-09-2021

DOI: $10.36552 /$ pjns.v25i3.596

\section{INTRODUCTION}

A cerebral aneurysm is a life-threatening disease that can be defined as an abnormal dilation of the vessel wall. ${ }^{1}$ Most commonly encounter at the weakest or diseased layers of the vessel, where there is proximal branching or a sudden turn in the artery, indicates that hemodynamic stress plays a major role. ${ }^{2}$ Generally accurate prevalence and incident is not possible due to cumulative factors including sudden and undiagnosed deaths without autopsy or radiological intervention. Aneurysmal intracranial subarachnoid hemorrhage is the most common neurosurgical emergency with the prevalence of about $6-10$ in 100,000 per annum. ${ }^{3,4}$ A ruptured aneurysm is linked with high mortality and disability associated with a 30-day mortality of 35\%, hardly $1 / 3$ of survivors can resume their normal life without dependency. ${ }^{5}$ Mortality of 30 to $50 \%$ who arrival at neuro-critical care is due to delayed ischemic even and rebreeding., ${ }^{1,6}$ Development of an aneurysm is most likely due to congenital but certain hereditary, degenerative, connective tissue disorder, inflammatory, infectious even neoplastic disease has a vital role in the aneurysm formation. ${ }^{6,7}$ Anterior circulation aneurysm is approximately 85 to $90 \%$ and the commonest among that is anterior communicating then posterior communicating followed by middle cerebral artery aneurysms. ${ }^{8}$

Four vessels digital subtraction angiography is the modality of choice, which not only helps in aneurysm diagnosis but also shows vasospasm. ${ }^{9}$
Both microscopic clipping and endovascular procedures are effective to obliterate the ruptured aneurysm from cerebral vasculature. Quality and outcome are further improved by additional intraoperative use of indocyanine green angiography that discloses the patency of parent artery as well as branching and perforating arteries during intraoperative application of the clip. $^{10}$

Overall postoperative outcomes depend on preoperative Hunt and Hess grading, Fisher grading, age of the patient, rate of re-bleeding, vasospasm. ${ }^{11}$

In this study we have assessed the management and outcomes of patients with aneurysmal subarachnoid hemorrhage that involved anterior cerebral circulation.

\section{MATERIAL AND METHODS}

\section{Study Design and Setting}

A Quasi-experimental descriptive study was conducted in the Neurosurgery Department of Peoples' university hospital Nawabshah Sindh, from November 2010 to December 2020.

\section{Inclusion Criteria}

All patients presented with aSAH due to ruptured anterior circulation aneurysm, Hunt and Hess grade I, II, III, IV, \& V and Fissure grading 1,2,3, \& 4 , Single or multiple aneurysms, berry or sacular aneurysms with age between 20 to 70 years were included.

\section{Exclusion Criteria}

Subarachnoid hemorrhage other than aneurysms rupture, fusiform, dissecting, posterior circulation aneurysms, blister aneurysms. Patients with age less than 20 years or above 70 years were also excluded.

\section{Data Collection}


All patients of aSAH admitted were assessed clinically by using Hunt and Hess grading. Later plain CT scan (Computed tomography) of the brain, CTA (Computed tomographic Angiography), or MRA (Magnetic Resonance Angiography), and DSA (Digital subtraction) angiography were done in patients with Hunt and Hess grade I, II, III. In grades III and IV, angiography and surgical intervention were performed when the patient was stabilized. Preoperative status of the patient, Intraoperative findings, and postoperative status along with surgical approach and management were enrolled and documented in proforma. A hospital ethical committee approval was received and close relatives or guardians were informed, counseled and written consent was obtained.

\section{Data Analysis}

All collected data were analyzed by using SPSS (Statistical Package for Social Services) version 25 data analyzer.

\section{Numerical Data}

Numerical Data mean and standard deviations were calculated for numerical data like age. Categorical data like gender, location, and type of aneurysm and type of surgical procedure, and clinical symptoms were presented as percentages and frequencies.

\section{RESULTS}

\section{Age, Clinical, and Radiological Assessment}

In 38 patients there were 40 aneurysms. Males were $n=23$ (61) and females were $n=15$ (39\%). The male to female ratio was $1.53: 1$ and the mean age at presentation was $50 \pm 25$ years. Plain CT scan of the brain, 4 vessel CT angiography, and digital subtraction angiography were performed, when presented to us with aneurysmal subarachnoid hemorrhage.

Patients diagnosed on $\mathrm{CT}$ angiography were 10 (53\%), on DSA 20 (26\%), on MR angiography 5 (13\%), and on plain CT of the brain, there were 3 (8\%). Patients that presented in Hunt and Hess grade IV were 8 , Grade V in 5, Grade III in 18, grade II in 7, and grade I in one (See Figure 1). Radiological assessment of SAH was done by Fissure scale, where grade 1 was reported in none, Grade 2 in 5, grade 3 in 20, grade 4 in 10 patients (Figure 2).

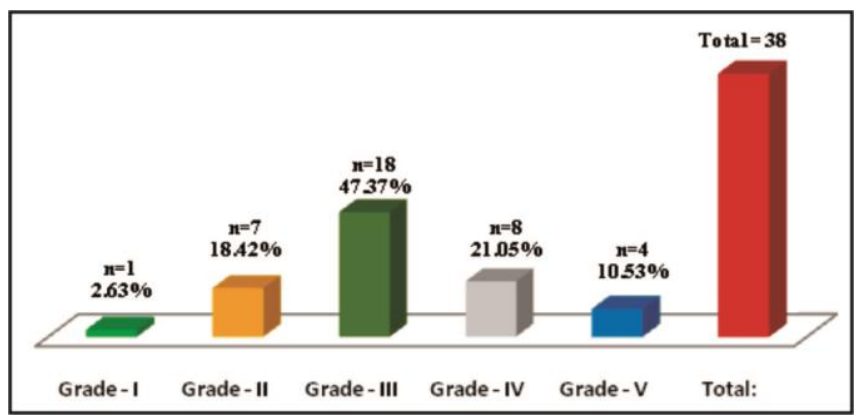

Figure 1: Number of patients in Hunt \& Hess Scale.

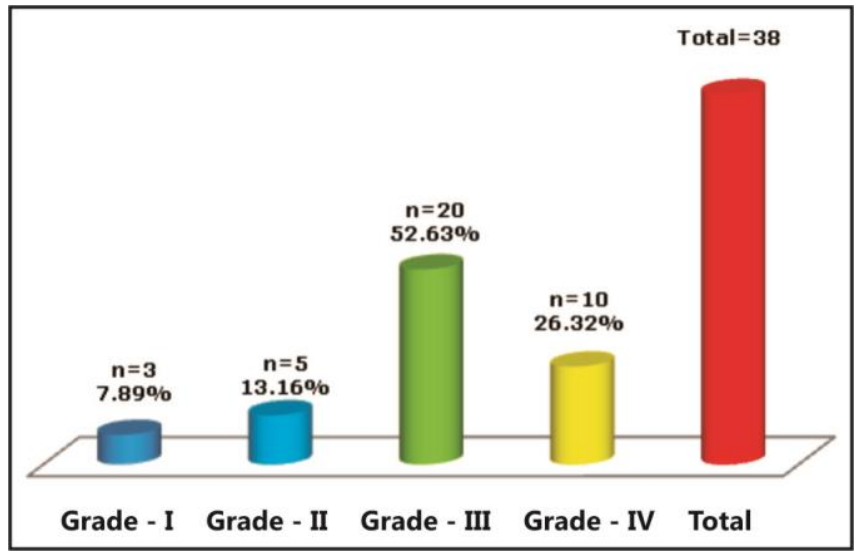

Figure 2: Number of patients in Fissure Grading.

\section{Incidence, Location, and Surgical Approach}

In our setup, we found MCA aneurysm in 18, Acom (Anterior communicating Artery) in 12, and others (see Figure3). Pteronial craniotomy was done in all cases $(n=26)$ except distal ACA 
aneurysm and some Acom, which were approached by frontal interhemispheric approach $(n=12)$. The time interval between presentation and surgical intervention was $28 \pm 16$ days. Surgical procedures 1 - clipping only. Simple Yasargil microsurgical clips were applied in 33 (82.5\%).

\section{Decompression and Clipping}

Aneurysms of M2 branch of MCA in 3 (7.5\%) who presented with huge ICB (Intracerebral bleed) with marked brain herniation and Hunt and Hess grade IV and $V$, emergency decompression craniectomy, and in those where clot evacuation plus clipping of aneurysm was done. 3 Libation. Suture ligation of giant MCA aneurysm was done 1 (2.5\%) and 4 in 3 (7.5\%) patients thrombectomy and excision of giant thrombosed aneurysm were successfully performed. The single clip was successfully applied to completely obliterate the aneurysm in 30 (75\%) patients, two clips in 5 (12\%) patients, and five clips in $1(2 \%)$ case.

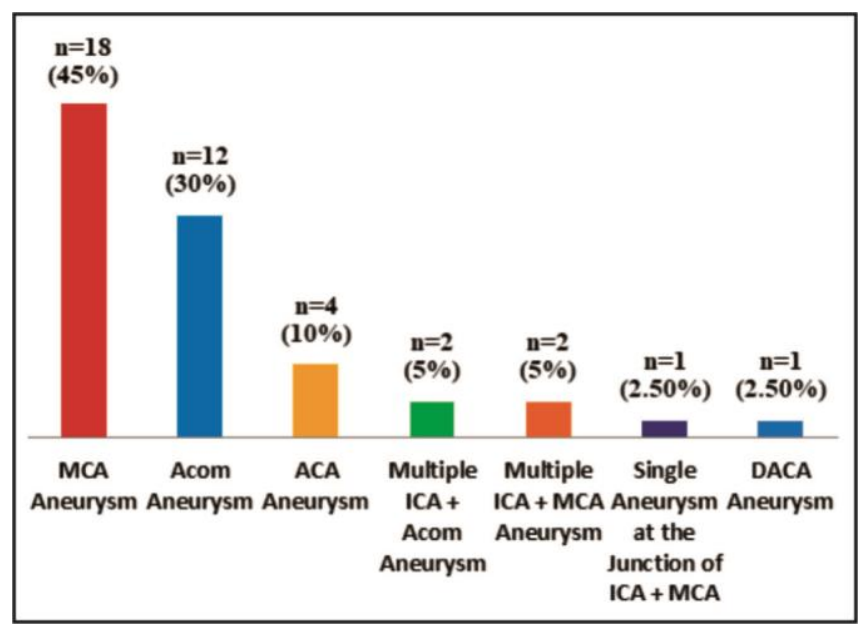

Figure 3: Location of Ruptured Aneurysms.

Key: MCA: (Middle Cerebral Artery Aneurysm), Acom: (Anterior Communicating Artery), ACA: (Anterior Cerebral Artery), ICA (Internal Carotid Artery), DACA: (Distal Anterior Cerebral Artery Aneurysm).

\section{Clip Application}

MCA aneurysms $n=2$ ruptured intraoperatively, which was successfully managed by applying 2 clips and 5 clips respectively and patients wokeup without inadvertent injury (Figure 4).

The patient to whom 5 clips were applied had mild postoperative hemiparesis. We had hypertensive plus smoker $(n=10)$, ischemic heart disease patient $(n=5)$, alcoholic $(n=10)$, diabetes mellitus ( $n=3$ ), female smoker of Biri (cheap cigarette made-up of unprocessed tobacco wrapped in leaves), and Hukka (it's cheap and local tobacco pipe with a long, flexible tube that draws the smoke through water and unprocessed tobacco contained in two bowls) $(n=2)$.

\section{Complications and Management}

A patient who developed immediate postoperative transient hemiplegia and aphasia $\mathrm{n}=1$, wound infection and CSF (Cerebro Spinal Fluid) leak $n=3$, CSF leak which was managed with acetazolamide $250 \mathrm{mg}$ orally twice a day, pressure bandage and continues epidural drain for 72 hours, Intracerebral bleed $(\mathrm{n}=1)$, extradural hematoma ( $\mathrm{n}=1)$, hydrocephalus $(n=3)$, impaired cognition ( $n=6)$, psychosocial impairment $(n=3)$, partial seizures $(n=2)$ and generalized seizures in $(n=1)$ were managed with a combination of valproic acid 500mg twice a day and Levetiracetam thrice a day. One patient died due to a respiratory problem.

\section{Prognosis}

Postoperatively, 8 patients improved from Hunt and Hess grade III to II in 2weeks. 5 patients from III to I in 4 months, 7 patients retained in grade III even after 6 months. 10 patients improved from grade II to I, two patients remained in grade 5 . Five patients got worse from grade IV to grade $\mathrm{V}$. This was collectively assessed by Good, fair, poor, and worst prognosis (see Table 1). A relatively 


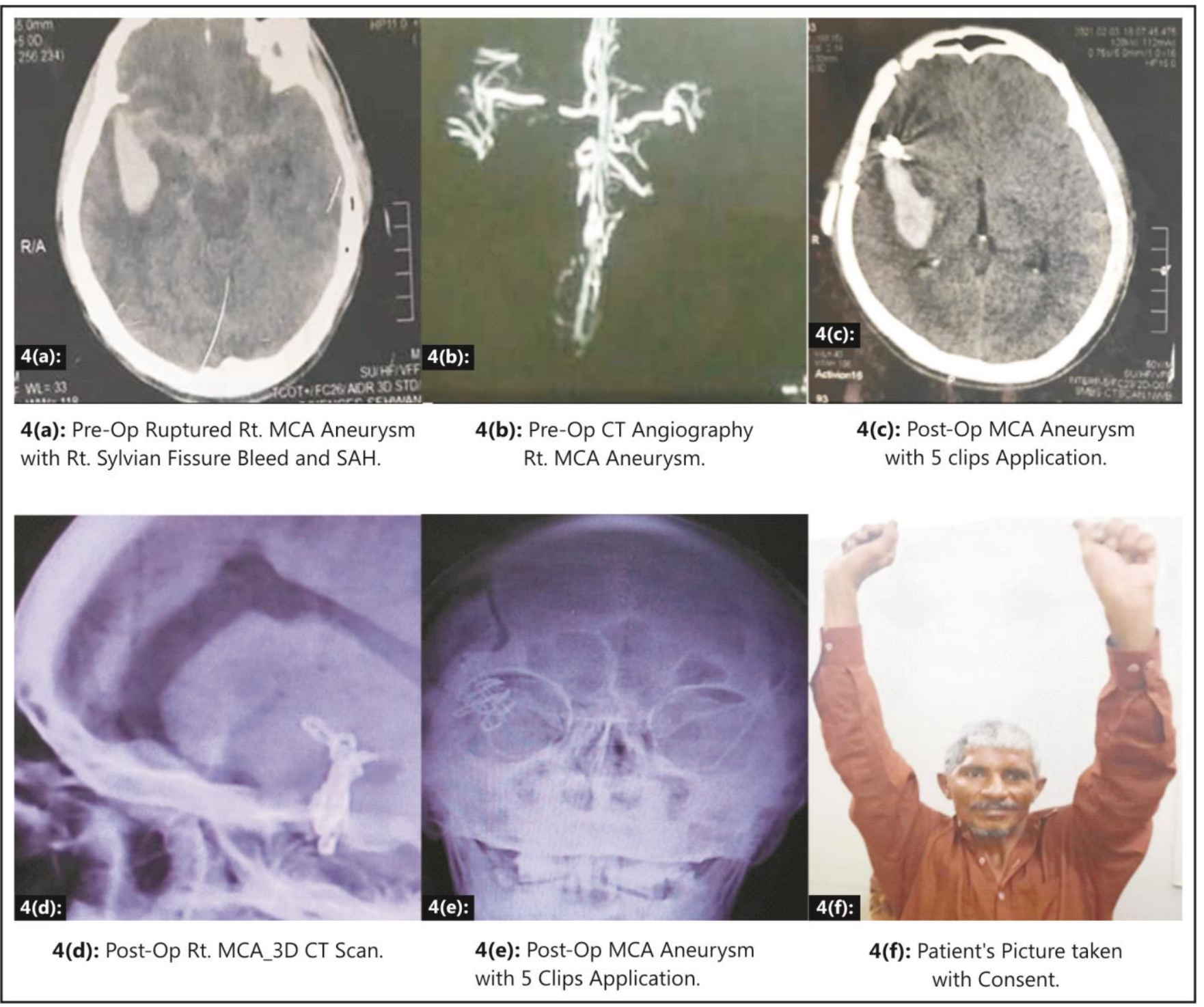

Figure 4: Computed Tomographic and Angiographic Images of Ruptured Middle Cerebral Artery Aneurysm Before and After Clips Application. Pictures Added with Consent and Permission of Patient.

Table 1: Clinical Assessment and Outcome.

\begin{tabular}{lcc} 
Outcome & Number & Percentage \\
$\begin{array}{l}\text { Good } \\
\text { (Hunt and Hess I,II+ mild disability }\end{array}$ & 23 & 60.53 \\
$\begin{array}{l}\text { Fair } \\
\text { Hunt and Hess III+ moderate } \\
\text { disability }\end{array}$ & 7 & 18.42 \\
$\begin{array}{l}\text { Poor } \\
\text { Hunt and Hess IV,V+ severe } \\
\text { disability }\end{array}$ & 7 & \\
$\begin{array}{l}\text { Worst } \\
\text { Death }\end{array}$ & & 18.42 \\
Total: & 1 & 2.63 \\
\hline
\end{tabular}

better outcome was noticed in the younger age group and the mean age at presentation was 45 years. Clinical assessment of the patient was followed up for a maximum of one year.

\section{Follow-up}

Regular follow-up was done after 2 weeks, 4 weeks, then 2 months, 6month and the final visit were done after one year. The patient who fails to visit was contacted in person. Ten patients were retained in a high dependency unit for maximum 


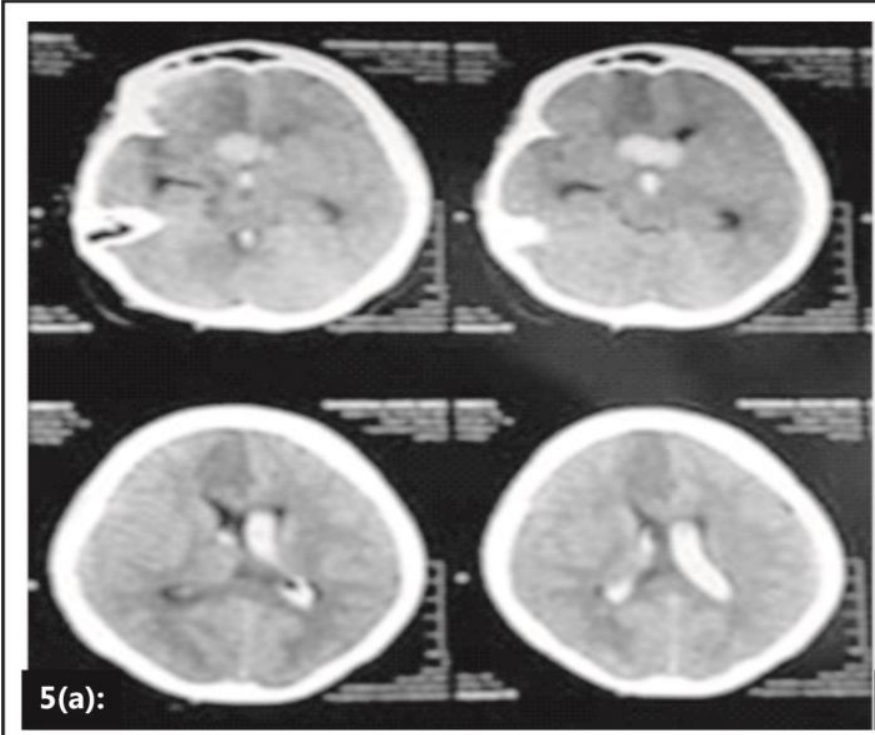

5(a): Plain CT Scan of Brain Showing Ruptured Rt. ACA Aneurysm with Interhemispheric and Intraventricular Bleed.

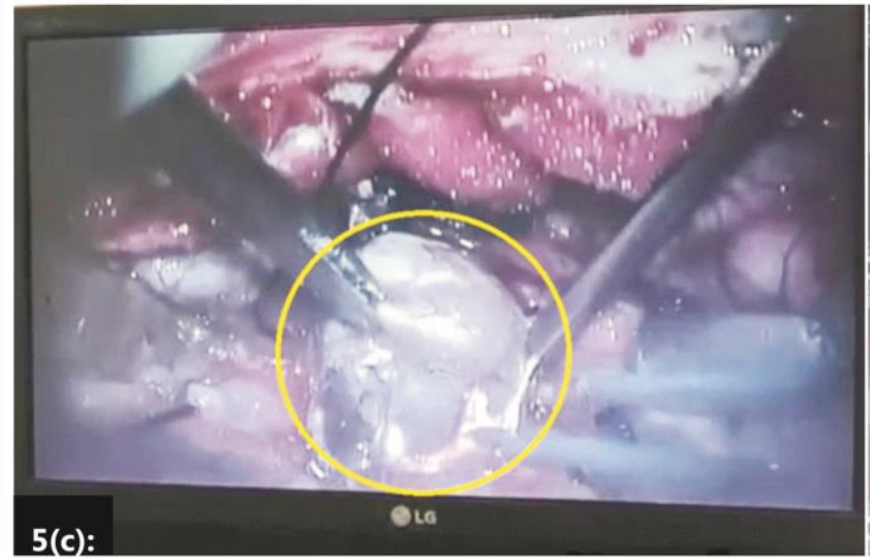

5(c): Intraoperative Image Showing Excision of Giant A2 Aneurysm.

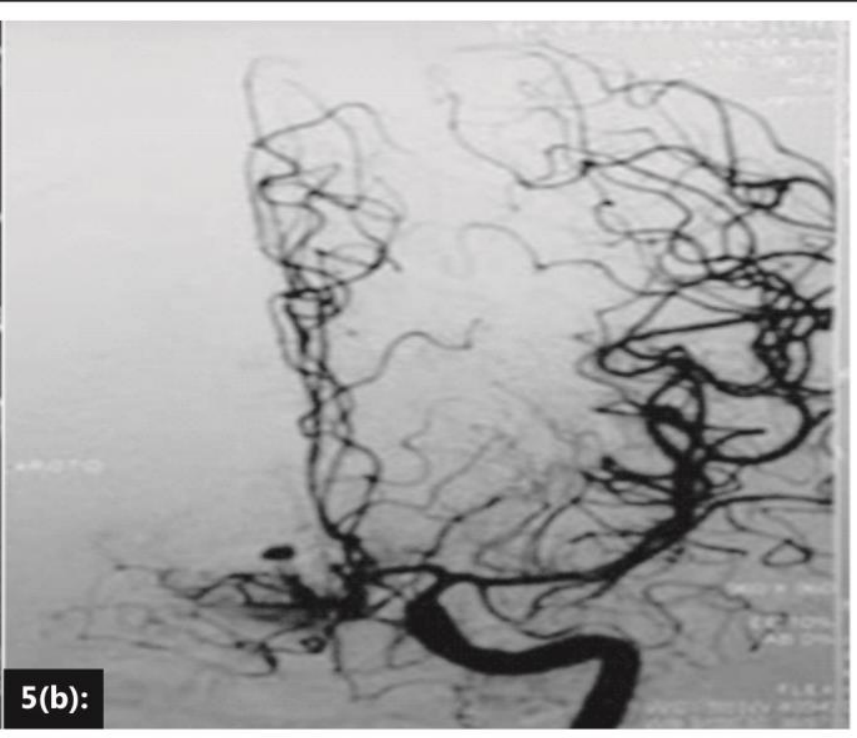

5(b): DSA Rt. ACA (A2) Aneurysm.

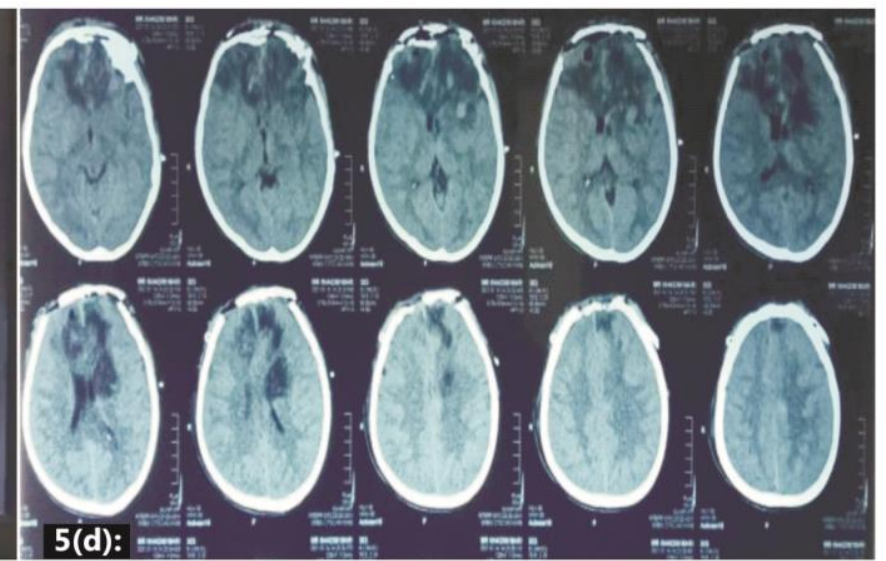

5(d): Post of CT Scan Rt. ACA (A2) Aneurysm Excision.

Figure 5(a): Plain Computed Tomographic and (b) Digital Subtraction Angiographic, (c) Intraoperative and (d) Postoperative (Excised) Images of Giant Right Anterior Cerebral Artery Aneurysm.

of 30 days because of chest infection, wound infection.

\section{DISCUSSION}

Ruptured intracranial aneurysm carries high fatality. Size, location of aneurysm along with the volume of hemorrhage, and surgeons' experience are the potential risk factors for a good outcome.
In our study, males dominated $n=23$ (61\%) with SAH which is similar to Wadd et al. reported males were $84 \%$ and females $60 \%$. Albeit Khan et al. had reported female dominancy with SAH $\mathrm{n}=11 \backslash 20,(55 \%))^{2,12}$ The reason could be a cultural and social preference for males, even mostly female patients who came with SAH their guardian preferred nonsurgical and home care management. Middle cerebral artery aneurysms 
were the commonest site about $45 \% \mathrm{n}=(18 / 40)$, which correlates with the study conducted by Rinne et al, in which out of 1314 intracranial aneurysms 690 (39\%) were MCA aneurysms. ${ }^{13}$ Patients with $\mathrm{M}^{2}$ (Segment of $\mathrm{MCA}$ ) ruptured aneurysm who presented in emergency with temporal/middle fossa intracerebral hematoma volume $>30 \mathrm{ml}$ with a sign of brain herniation and Fissure grade 4 and 5 were taken directly to emergency operation theater for decompression of clot and clipping of ruptured aneurysm was done by the most senior neurosurgeon and postoperative kept in ICU. A young man who presented with giant MCA aneurysm $n=1$, partial internal debulking of the thrombosed aneurysm with silk suture ligation was done and the patient successfully recovered. ${ }^{14}$ Out of 3 giants thrombosed aneurysm 2 were excised and clipped, $n=1$ of $A 2$ (branch of ACA) aneurysm complete excision of the thrombosed aneurysm was done without clip application postoperative patient experienced the akinetic type of mutism, new-onset hemiparesis, and aphasia, which was completely recovered over 3 months (Figure 5). Acom aneurysm was the $2^{\text {nd }}$ most common site $\mathrm{n}=12$ (30\%).

Right-sided Pterional approach preferred ( $n=$ 18) than left side except in MCA aneurysms which was approached from ipsilateral to aneurysmal bleed and when dominant vessel on the left side $(n=8)$.In case of multiple aneurysm clinoidal internal carotid artery plus Acom aneurysm, anterior clinoid was drilled, the temporary clamp was applied on ICA for $2-3$ minutes and aneurysm that was arising from clinoidal segment was first clipped followed by clipping of Acom aneurysm. The same strategy was applied on multiple aneurysms of ICA and MCA aneurysms. We have $n=1$ (2.6\%) postoperative mortality while Lafuente and Maurice-Williams had mentioned operative mortality of $n=2$ (2.6\%) and $0.4 \%$ mortality was reported by Lahecka et al, for DACA aneurysms. Jahangir et al. mentioned $15 \%$ mortality. ${ }^{15,16,12}$ Although DSA is considered to be ideal for diagnostic modality for any vascular anomalies and lesion, we have considered it in patients that can afford the cast of DSA and are stable to travel from our setup to where DSA is available. Mostly 6 or 12-hours after surgery repeat CT scan of the brain was done that depends on the post-op status of the patient. We noticed hydrocephalus in $\mathrm{n}=3$ (7.89\%) and infection $n=3$ (7.89\%), while Taha et al. mentioned 2 (56\%) had hydrocephalus and $0 \%$ infection was reported by them. ${ }^{17}$

The earliest intervention within 72 hours was done in MCA aneurysm $n=3$ with IC bleed and sign of brain herniation. Keeping in mind the general and neurological status of patient and Hunt and Hess grading, period of vasospasm, unavailability of DSA at our setup or nearby, mostly $\mathrm{n}=35$ late surgical intervention of maximum $28 \pm 16$ days done. Most neurosurgeons in 1970 preferred surgery after vasospasm due to swollen brain, surgical manipulation is quite lethal. ${ }^{11,18}$ In 2016, Mees Dorhout et al, evaluated that early intervention has better outcomes as compared to late. ${ }^{19}$

In our study patients that survived initial hemorrhage and developed vasospasm were managed by triple $\mathrm{H}$ therapy to achieve relative hypertension, hypervolemia, and hemodilution, with the help of crystalloid and osmotic (mannitol) infusion. During that period anticonvulsant and calcium channel blockers, stool softeners were prescribed and low dose corticosteroids were continued and tapered regularly.

In 2016, Orakdogen et al. analyzed that aneurysm size, WFNS grade, vasospasm, and age of the patient are the most prognostic factors for any aneurysm surgery. ${ }^{20}$ Bohnstedt and Samaha analyzed that Hunt and Hess and neurological status on admission has a direct impact on outcome. 21,8

In this study we have $\mathrm{N}=23$ (60.5\%) patients had good, 7 (18.42\%) had fair and $n=7$ (18.42\%) poor and $n=1$ (2.6\%) worst outcome was 
noticed. A study analyzed by Wadd et al. reported, no disability $=23$ (32.9\%) in grades I, II, slightly disability $\mathrm{n}=23(33.9 \%)$ in grade 3 , moderate disability $n=24$ (34.3\%). The overall favorable outcome of coiling that was reported was about $68.6 \%$, the unfavorable outcome was (33.1\%) and death in $4.3 \%$ of patients. ${ }^{2}$ Koivisto et al, reported poor outcomes in $33 \%$ of patient. ${ }^{22}$. David et al, reported operative mortality of $8.6 \%$ in the giant intracranial ruptured aneurysm, while Lafuente and others reported $2.6 \%$ surgical mortality by well experiment surgeons. ${ }^{23,15}$ Even with limited diagnostic and surgical resources like unavailability of digital subtraction angiography to diagnose vascular anomalies and diffusion magnetic resonance angiography to evaluate the delayed cerebral ischemic event along with the very low economic status of our patients we have safely and successfully managed the ruptured anterior circulation aneurysms with microsurgical clipping, suture ligation and excision of the thrombosed aneurysm. Some selected cases of ruptured MCA aneurysms can be managed by decompressive craniotomy, clot evacuation, and aneurysmal clip application.

\section{Recommendation}

Intraoperative use of a magnificent microscope with precise surgical skills, safe, accurate, and meticulous handling of the ruptured aneurysm, and perforating cerebral branches can achieve good results.

\section{Limitation}

It was a single-center study that covers most of the population of interior Sindh. Age below 20 years was not studied. Ruptured intercavernous internal carotid artery aneurysm and posterior circulation aneurysms were not included. We had a limited number of patients with limited diagnostic and surgical resources.

\section{CONCLUSION}

Microsurgical clipping provides safe and complete obliteration of the ruptured cerebral aneurysm. Rarely aneurysm can be managed successfully by ligation and excision depends on underlying pathological condition. Presenting neurological status, degree of hemorrhage, age, comorbid condition, and expertise of neurosurgeon has a major impact on the outcome.

\section{ACKNOWLEDGMENT}

Mr. Imran Ali, Computer Operator, in the Department of Neurosurgery, PUMHSW, Nawabshah has contributed to the completion of this article by rendering his services in grammar accuracy and typographical correction.

\section{REFERENCES}

1. Wecht DA, Awwad IA. Subarachnoid Haemorrhage: Principle of neurosurgery. 2nd ed. Grossman RG, Loftus CM (ed). Philadelphia: Lippincott-Raven Publishers, 1999: 297-308.

2. Wadd IH, Haroon A, Habibullah. Aneurysmal Subarachnoid Hemorrhage: Outcome of Aneurysm Clipping Versus Coiling in Anterior Circulation Aneurysm. Journal of the College of Physicians and Surgeons Pakistan, 2015; 25 (11): 798-801.

3. International Study of Unruptured Intracranial Aneurysms Investigators. Unruptured intracranial aneurysms-risk of rupture and risks of surgical intervention. New England Journal of Medicine, 1998 Dec. 10; 339 (24): 1725-33.

4. Linn FH, Rinkel GJ, Algra $A$, et al. Incidence of subarachnoid hemorrhage: role of region, year, and rate of computed tomography: a metaanalysis. Stroke, 1996; 276: 25-9.

5. Fukuda $S$, Koga $Y$. Hyperexemia during the hyperacute phase of aneurysmal subarachnoid hemorrhage is associated with delayed cerebral ischemia and poor outcome: A retrospective observational study. J Neurosurg. 2021; 134 (15): 1-8. 
6. Fayyaz M, Hassan MA, Attique MH. Risk factors and early prognosis in stroke. Ann KE Med Col. 1999; 5: 12-5.

7. Rhoney DH, McAllen K, DeRyke XL. Current and future treatment considerations in the management of aneurysmal subarachnoid haemorrhage. J Pharm Pract. 2010; 23: 408-24.

8. Samaha E, Rizk T, Nohra G, Mohasseb G, Okais N. Intracranial arterial aneurysm: from diagnosis to treatment. A retrospective study of 46 surgically treated cases. J Med Liban. 1998; 46: 1225.

9. De Oliveira JG, Beck J, Seifert V, Teixeira MJ, Raabe A. Assessment of flow in perforating arteries during intracranial aneurysm surgery using intraoperative near-infrared indocyanine green video angiography. Operative Neurosurg. 2007; 61-72.

10. Nieuwkamp DJ, Rinkel GJ, Silva R, Greebe $P$, Schokking DA, Ferro JM. Subarachnoid haemorrhage in patients $>$ or $=75 y$ years: clinical course, treatment and outcome. J Neurol Neurosurg Psy. 2006; 77: 933-7.

11. Bohm $E$, Hugosson R. Experiences of surgical treatment of 400 consecutive ruptured cerebral arterial aneurysms. Acta Neurochir (Wein). 1978: 40-43.

12. Khan MJ, M. Nasir $H$, Ali $S$. Outcome of Microsurgical Clipping of Ruptured Anterior Circulation Aneurysms. Pak. J. of Neurol. Surg. 2019: 277-281.

13. Rinne J, Keisuke I, HU Shen et al. Surgical management of aneurysms of middle cerebral artery, Henry H. Schemidek, Operative neurosurgical techniques. $5^{\text {th }}$ ed. Saunders: Elsevier Publishing, 2006: 1144-1166.

14. Raza BS, Muzammil D. Silk ligation and Excision of Giant MCA aneurysm as Alternative Method of Treatment. Pak J Neurol Surg. 2018; 22 (4): 196-8.

15. Lafuente J, Maurice-Williams RS. Ruptured intracranial aneurysms: The outcome of surgical treatment of experienced hands in the period prior to the advent of endovascular coiling. J Neurol Neurosurg Psy. 2003; 74 (12): 1680-4.

16. Lehecka $M$, Lehto $H$, Niemelä $M$, Juvela $S$, Dashti $R$, Koivisto $T$, Ronkainen A, Rinne J, Jääskeläinen $J E$, Hernesniemi JA. Distal anterior cerebral artery aneurysms: treatment and outcome analysis of 501 patients. Neurosurgery, 2008; 62 (3): 590-601.

17. Taha MM, Alawamry A, Abdelbary TH. Outcome of microsurgical clipping of anterior circulation aneurysms during the period of vasospasm: single center experience in Egypt. Egyptian Journal of Neurosurgery, 2019; 34 (1): 1-6.

18. Kassell NF, Drake C. Timing of aneurysm surgery. Neurosurgery, 1982; 10 (4): 514-9.

19. Dorhout Mees SM, Molyneux AJ, Kerr RS, Algra A, Rinkel GJ. Timing of aneurysm treatment after subarachnoid hemorrhage: relationship with delayed cerebral ischemia and poor outcome. Stroke, 2012; 43 (8): 2126-9.

20. Orakdogen $M$, Emon ST, Somay $H$, Engin $T$, Ates $O$, Berkman MZ. Prognostic factors in patients who underwent aneurysmal clipping due to spontaneous subarachnoid hemorrhage. Turk Neurosurg. 2016; 26 (6): 840-8.

21. Bohnstedt BN, Nguyen HS, Kulwin CG, Shoja MM, Helbig GM, Leipzig TJ, Payner TD, Cohen-Gadol AA. Outcomes for clip ligation and hematoma evacuation associated with 102 patients with ruptured middle cerebral artery aneurysms. World Neurosurg. 2013; 80: 335-41.

22. Koivisto $T$, Vanninen R, Hurskainen H. Outcomes of early endovascular versus surgical treatment of ruptured cerebral aneurysms: a prospective randomized study. Stroke, 2000; 31: 2369-77.

23. David G. Piepgras, Vini G. Khurana and Jack P. Whishant. Ruptured giant intracranial aneurysms part II. A retrospective analysis of timing and outcome of surgical treatment. J Neurosurg. 1998; 88: 430-435. 


\section{Additional Information:}

Disclosures: Authors report on conflict of interest.

Ethical Review Board Approval: the study was confirmed to the ethical review board requirements.

Human Subject: Consent was obtained by all patients / participants in this study.

Conflict of Interest:

In compliance with the ICMJE uniform disclosures form, all authors declare the following:

Financial Relationships: all authors have declared that they have no financial relationship at present or within the previous three years with any organizations that might have an interest in the submitted work.

Other Relationships: all authors have declared that there are no other relationships or activities that could appear to have influenced the submitted work.

Funding or sponsorship: Nil.

\section{AUTHORS CONTRIBUTIONS}

\begin{tabular}{|l|l|l|}
\hline Sr.\# & Author's Full Name & Intellectual Contribution to Paper in Terms of: \\
\hline 1. & Fahmida Arab Mallah & Paper writing, referencing, and data calculations. \\
\hline 2. & Abdul Razaque Mari & Interpretation of results and final literature review. \\
\hline 3. & Muzammil Dilber Prof. & Data collection and calculations. \\
\hline 4. & Shams Raza Brohi & Analysis of data and quality insurer. \\
\hline 5. & Hamid Akbar Shaikh & Literature review and manuscript writing. \\
\hline 6. & Syed Aamir Shah & Study design and methodology. \\
\hline 7. & Imran Mirbahar & Analysis of data and interpretation of results. \\
\hline
\end{tabular}

